\title{
Murder misdiagnosed as SIDS: a perpetrator's perspective
}

\author{
J Stanton, A Simpson
}

\begin{abstract}
Aims-Child murder misdiagnosed as sudden infant death syndrome (SIDS) is a difficult area to study. We present a perpetrator's descriptions to enrich clinicians' knowledge of possible presenting features of this phenomenon.

Methods-Interview material was collected as part of a qualitative study of maternal filicide performed from a naturalistic paradigm in order to access the perpetrators' view of events. The woman participant has been convicted for three child murders and two attempted murders which were initially misdiagnosed as SIDS. Interviews were done in the participant's home with her partner present, while she was on leave from prison. Semistructured interviews were conducted, recorded, transcribed, and analysed for themes. Specific ethical permission was gained to present this case in isolation and the paper was written in consultation with the woman described.

Results-She described initial intense attachment to her first victim and described killing her because she was unable to bear her apnoea attacks and her fear of losing her. She described difficulty grieving for this child and subsequent failure to attach to her next child or feel for the other victims.

Conclusions-Expressions of intense attachment to an infant and description of intense grief over a death in a way which engages compassion should not deter a paediatrician from considering the possibility of the parent having killed the child. (Arch Dis Child 2001;85:454-459)
\end{abstract}

Keywords: SIDS; infanticide; child murder

Studies of sudden infant death syndrome (SIDS) have identified important risk factors. Educating parents not to put infants to sleep prone may have contributed towards the decline in SIDS. ${ }^{1}$ However, lack of specific defining features for the syndrome has meant that deaths due to unnatural causes, such as suffocation, where there have not been postmortem findings to indicate a cause of death, have been misdiagnosed as SIDS.

In the early 1980s, Emery ${ }^{2}$ and Taylor and Emery $^{3}$ suggested that $10 \%$ of deaths classified as SIDS may not be due to natural causes. Improvements in a range of areas are contributing to the decrease in the number of deaths of infants from natural causes, ${ }^{4}$ but limited progress has been made in identifying or preventing infant deaths due to filicide. This difficulty is being addressed. For example, guidelines have been published by the Committee on Child Abuse and Neglect ${ }^{5}$ with respect to identification and investigation of sudden infant deaths.

Meadow ${ }^{4}$ has described clinical features associated with 81 children identified as having been killed by their parents. This series was drawn from 18 years' experience and thus represents only a small proportion of infant deaths. Dramatic and controversial in the study of a related area have been the covert video recording $s^{67}$ made of parents of children deliberately engaging in life threatening child abuse. While the numbers are again small they have served as graphic illustrations of the existence and form of a type of child abuse which is difficult for clinicians to imagine. The necessity for such evidence is illustrated by the report from Samuels and colleagues ${ }^{6}$ of the incredulity some judges and magistrates expressed that a parent could have behaved in such a way, even after they had viewed the video evidence.

Thus, studies to date have focused initially on the question of whether child murder has been misdiagnosed as SIDS and progressively on identification and general features of such cases. Our paper provides an unusual perspective. It is a summary of a verbatim first person account by a woman who smothered two of her own children. These deaths were misdiagnosed as SIDS. They were followed by further assaults on other people's children, one of which resulted in death. Its value is in the way she presents herself to the listener, rather than as a presumed account of her underlying psychological processes.

Background to the case

$M$ is a white woman, in her early 20 s at the time of the events. She was living in a stable common law marriage relationship when her own two children died; she became involved in another committed relationship before the final murder. This relationship was still extant at the time of the interview. In the context of extensive therapy in prison she acknowledged her guilt and described smothering the infants with a large pillow.

\section{Summary of events}

This summary is drawn from police and court records which included expert medical testimony, but the authors did not have access to original hospital and medical files.

$M$ spent five weeks in hospital during her pregnancy with D1 due to toxaemia and high blood pressure. D1 was delivered at term after 
a long labour resulting in a caesarean section. $M$ had reported breathing problems with D1 and M's mother was reported to have found D1 with breathing problems at two and a half months. D1 was hospitalised prior to her death, but died at home, aged 3 months, in the morning, two hours after having been seen well. Postmortem findings described a well nourished infant. There was no visible blood but fine white froth was noted in the larynx, trachea, and main bronchi, and mild swelling in the lungs (reviewed in Becroft and Lockett ${ }^{8}$ ).

D2 was born two years after D1's death. M again had toxaemia and high blood pressure, leading to hospitalisation during her pregnancy. D2 was induced at term and labour was again prolonged, resulting in a caesarean section. D2 was hospitalised at two and a half weeks of age with breathing problems, signs of respiratory tract infection, and failure to gain weight which improved in hospital. Weight gain on return home was satisfactory. She died during the day at two and a half months. Postmortem findings described blood and red foam around her nose and mouth and dried blood in her nostrils. Her lungs were large and congested and mottled with haemorrhages.

Seven months after D2's death, an infant aged 4 months had an episode described as a "near miss cot death" while in M's care. This happened again with the same child when she was aged 10 months. Two months later another infant aged 5 weeks had a "near miss cot death" in M's care. Eight months after this M had a hysterectomy. Three months after this another child, aged 8 months, died in her care.

These events resulted in three convictions of murder and two of attempted murder, for which $M$ received a custodial sentence. She did not have a major psychiatric illness, but was diagnsed with a severe personality disorder of cluster B type. ${ }^{9}$

\section{Methods}

The account is based on verbatim records from two semi-structured interviews with the perpetrator. These were performed as part of an exploratory study of maternal filicide described elsewhere. ${ }^{10}$ She was interviewed on home leave towards the end of her jail term, 17 years after the first death. Because of the risk of identification, specific ethical permission was obtained to present the data from this single case, rather than as an amalgam of cases. The woman involved has been consulted over the development of the paper, reviewed each draft, and given written permission for submission for publication. She was also offered a veto over the inclusion of any specific material or interpretation. To maximise anonymity the woman will be referred to as $\mathrm{M}$, her daughters as D1 and D2, and their father as F.

We acknowledge M's courage and generosity in enabling this article to be written. While all (including herself) are likely to judge her harshly for her actions, she has suffered a great deal. She has lost her children, any chance of being a mother, or having a mothering role, and carries with her forever the identity of "child murderer". We asked her permission to present her words in this way in the hope that it may help doctors identify some other woman in time to stop her earlier than $M$ was stopped. She is aware of the limits to confidentiality, but despite this has supported the project. Working within a naturalistic paradigm, ${ }^{11}$ we have attempted to present her descriptions authentically and respectfully.

\section{Results}

D1, A LONGED FOR, SPECIAL BABY

A powerful theme throughout the transcript was M's interest in children.

That's all I ever wanted, was to be a housewife and a mother, that's all I wanted out of life. Boring I know, but that's all I wanted.

Before entering a relationship with $F, M$ described having had 13 miscarriages. She described D1 as planned and long awaited.

I believed that I would never ever get pregnant and I was so scared. ... I was just trying and trying to get pregnant ... oh, I cried when I got my period. ... It was just disaster every time I got my period.

Conception of D1 was described as a source of great joy to the couple.

You know $[\mathrm{F}]$ was just so rapt, he was just so tickled pink. ... as soon as I found out that I was pregnant I mean we went through and bought a pram and he would buy things in kitsets and stuff like that and we did things together.

She recalled the pregnancy and delivery, however, as difficult with long periods in hospital during the pregnancy and protracted labour culminating in a caesarean section. However, despite being exhausted after the delivery $M$ described an ecstatic response to her new baby.

\section{... this tiny little bundle, yeh, I couldn't believe it. ... It was a really neat feeling. Just having this little girl. ... all I'd ever wanted, a baby of my own.}

She also described D1 as a particularly endearing baby.

Very content, extremely content ... she was amazing, I mean you know I'd go down to the shops or something and she'd be just lying in her pram and looking all around ... She was a really good baby. I couldn't have asked for a better daughter.

$M$ described the early days of her motherhood with joy.

... I wanted heaps of kids, you know, I was quite, quite happy. ... I was able to have this beautiful little girl and she was mine.

... she was my world, she was everything to me ...

My days were spent with me and my daughter, I couldn't wait to push $\mathrm{F}$ out the door to go to work, ... we'd stand at the door and I had D1 in my arms, you know, and he'd kiss his daughter goodbye and I'd say "wave, bye, bye to dad" and I'd get her wee hand and you know ... she'd be in her bouncinette or something and I'd be doing the housework. 
ONSET OF BREATHING PROBLEMS

$M$ described how, once the breathing problems started, the "spell" was broken.

... I was quite happy, I'd found my niche in life, like I'd got what I wanted, kind of thing until this other thing [breathing problems]. ... I was petrified.

M described having had a possessive streak as a child, which came to the fore at this time.

After the breathing problems ... I became very obsessed with her, extremely obsessed, I wouldn't move without her at all. ... I just wouldn't leave her for one second.

She described that getting an apnoea alarm increased, rather than decreased the pressure.

... and oh, look, it would just go off and I'd tear in there or $\mathrm{F}$ would tear in there and nine times out of ten it was just, the alarm being faulty.

It was just continual pressure, just the whole time, it was really hard, ... I wasn't getting any sleep, and people would offer to have her, but, oh, I wouldn't let her out of my sight. ... No, no, I didn't trust anybody.

She was my daughter, I was very possessive of [D1], extremely possessive. ... Mum came down and I remember screaming at Mum one night, ... "don't touch her, don't touch her".

$\mathrm{M}$ described following medical advice to give up the apnoea alarm and move D1 out of her room.

The doctor said "Well look, you should let nature take it's course, if it's going to happen, it's going to happen, it's your decision". So, we took her off it [the apnoea alarm].

We had her [D1] in our bedroom for a while, but the doctors decided it would be best for her to get used to her own environment in her own room.

She struggled to make sense of events.

$\ldots$ and I couldn't understand why it was happening, because I mean she was very wanted.

$M$ was indignant at suggestions made later that the breathing problems may not have been genuine but a symptom of Munchausen's syndrome by proxy.

They [TV documentary] said that [D1] only had breathing problems when she was only alone with me, that is not right, there was about three occasions.

THE FIRST MURDER

M described the killing of her much loved and wanted daughter as a "mercy killing"- that is, where a child is killed to prevent them having to go through real suffering. There was a crisis when D1 was taken into hospital and put in an oxygen tent.

... she was in the oxygen tent with tubes and I couldn't handle it, I really couldn't, sorry.

When asked what she could not handle she went back over her experience.
Seeing her like that. This tiny little baby, oh just tubes everywhere, you know, I remember sort of wanting to sort of just pick her up and cuddle her and I couldn't because she was attached to all these tubes and so forth.

It was the fact that I couldn't hold my child.

Oh yes, she was struggling to breathe and you could see it. She was under a tent and I remember screaming at the nurse cause she wouldn't let me pick her up ...

$\mathrm{M}$ also described the killing as a way of having some control over when she lost her daughter.

I much rather of done it myself, then have her die, actually I know it sounded really screwed up, but that's the way, I believe, that's the way that I felt, I just didn't want her to, I was so scared that she was gonna die, I really, really was.

I got really, really scared. ... to have someone else take her away from me, you know, ... if she was taken away from me I just couldn't ....

... that's why I killed her, because I didn't want to lose her.

GRIEVING FOR D1

$M$ described being unable to contain her grief once D1 was dead.

After I killed her, the guilt, oh God, I completely broke down after she died.

... I just lay in bed and I cried, I cried and I cried and $I$ cried and there was nothing he $[F]$ could do with me, you know and in the end Dad came in and cause I was really close to my dad.

... I just remember just throwing myself whole body over this coffin, I was just absolutely hysterical.

Like I remember [friend with a baby] coming up to me saying "oh look if it takes the hurt and the grief away I would give you [her baby]", and I remember attacking her at the funeral. ... That was just grief.

$M$ described her sense of guilt and grief as affecting her every moment.

She was like, she was with me practically 24 hours a day every day kind of thing.

Almost like every child I saw in the street, I saw [D1], it was just really quite twisted it's just a real grief, which I hadn't dealt with, of course with all the other guilt and so forth and knowing what I'd done.

She experienced what she described as a "breakdown"

... after she died people got quite concerned because I wouldn't let anyone in [D1]'s room, no one was to go in that child's room, the room was set up and left, like her cradle and everything, the bouncinette and all her toys and all her clothes and I'd go in there every day and clean and vacuum it and stuff like that. $\mathrm{F}$ came home one night and found me sitting, ... I used to sit in the rocking chair and have her in my arms and rock her and talk to her after I'd fed her. ... and I was sitting in this bloody room in this rocking chair and that's when he put his foot down,... I think that was more or less the start of the breakdown. 
I just couldn't cope, not sleeping, just went really, really quite haywire and $\mathrm{F}$ was very worried about me, ... he spoke to Mum and Dad about it and Dad said "well I think we better take her to the doctor" and the doctor took one look at me and that was it.

She was admitted to a psychiatric facility and prescribed medication which she did not take. She described that she was discharged when she appeared to have settled down.

$M$ described being alone in her grief.

The hardest part about it, like when I had my breakdown I couldn't tell anybody, sure, I had a breakdown because I'd lost my daughter, which was part truth, but the reason I lost her was because I had smothered her and couldn't tell anybody.

M'S SECOND BABY

$M$ described the conception of her second daughter as quite different.

I didn't want her. I got pregnant because $\mathrm{F}$ and I were going to split up, we were on the verge of splitting up. We decided we wanted another child, and so I got pregnant and I just didn't want

it. ... it was just more less to hang on to $\mathrm{F}$.

She described that when she was pregnant with her second daughter she did not take care of herself as she should. There were also problems with the pregnancy and delivery.

... there was problems with me haemorrhaging before I actually had her. ... In and out of hospital, in and out, in and out, and then when I had her, she was 2 days old before I actually saw her, cause I'd haemorrhaged in theatre. ... I woke up too spaced out to even care and said "what have I had?" kind of thing. ...

When D2 was born $\mathrm{M}$ described herself feeling nothing for her.

There was no bonding, absolutely no bonding, whatsoever.

[D2] just was not wanted, I mean, just not wanted at all.

She also described D2 as quite a different sort of baby.

I could hear her before I actually saw her. ... Oh, she wasn't crying, she was having a temper tantrum. ... this kid screamed from the day that she was born to the day that she died.

$\mathrm{M}$ also described how difficult she found it to cope with this crying.

I can't handle hearing the baby cry, I hate it, and I feel really helpless ... it was just I was tired, I really resented this child, really resented her, and right from the beginning because all I wanted was [D1].

M described her level of functioning deteriorating; always a meticulous housewife, she started drinking, did not keep the house clean and would not get dressed all day.

$M$ was clear that no one was aware how much she resented D2 and she felt unable to tell anyone. She described a trusted GP who may have been available to help but she was not letting him know as she did not want to be seen to be not coping.
I was too far gone. I was just, like just not there, do you know what I mean. ... not mentally sick, but just, you know, couldn't talk, and of course after [D2] died I just got from bad to worse.

$M$ described feeling anger rather than concern when D2 cried. She described killing D2 in a state of anger.

I knew exactly what I was doing, oh yes, I just, oh you know, I hated having to get up to feed her, I hated doing this, I hated doing that. ... Well, I thought, OK. I never got caught for [D1]'s death, I don't want this child, how am I gonna get rid of it, you know, so I smothered her the same way as I did with [D1].

ASSAULTS ON OTHER CHILDREN

After the deaths of her children she repeatedly sought childcare work, a pattern she attributed to a need to be with children.

Yeh, that driving need. That possess/possessive feeling. Yeh, wanting to be, have something to call them my own I guess.

In general she described enjoying being with them, but this was different for two of the children she attempted to smother. The motive in these cases was revenge for actions of their parents. With one of these $\mathrm{M}$ described it as a combination of revenge for past events and having a child the same age as D1. The other was in retaliation for the mother having broken up her relationship with her partner. She described how devastating she found it.

Yeh, it was um, oh it was really hard, it was really hard for me because I mean, suddenly you know I had it all together, you know (before the children's deaths) my life together and that, and suddenly one bombshell hits, I lose [D1] and [D2] dies, and then I lose the man that I loved. One, two three. It just went on and on and on.

With one attempted smothering $M$ acknowledged that the baby's needs did not exist for her at all and described such bitterness and hatred that she had wanted the baby dead and offered to babysit with that aim.

I got no pleasure out of it [being with the baby] whatsoever. None whatsoever. ... It was only because, um, it was more or less to get back, well with [the baby's mother], ..., I mean she was the girl that went and had an affair with $[\mathrm{F}]$, and split us up. I mean, I really wanted to get to her.

With the other attempt she described disliking the baby.

I remember thinking "I don't really like you".

These differed from the murders which she described as not premeditated.

After these attempts $M$ described seeking medical help for menorrhagia, which led to her having a hysterectomy.

Then he [GP] made an appointment at [women's hospital]. Oh we'll tie your tubes. That's not going to stop it. So meanwhile I am still haemorrhaging and still going through this hassle. Then I finally go and see a private gynaecologist at [local clinic]. He examined me looked through my [obstetric] history, said "sorry, no go. ... it would be dangerous for you to get pregnant again, so we are going to have to give you a hysterectomy". 
$M$ described that although she wanted another baby, in retrospect she agreed with the gynaecologist.

I am glad that I didn't get pregnant, it would have been just another disaster. ... for the simple reason being that I still hadn't got over [D1]. It was [D1] that I wanted, not just another baby. I still hadn't gotten over the grief of losing [D1].

M described having had the hysterectomy as part of the basis for the jealous and vengeful feelings which were part of the third murderthe smothering of a 9 month old neighbourhood baby she was babysitting.

... the [final] murder was straight out revenge. It was something that, "you've got what I want and I'm having it". .. "why should you have something that I can't have?".

\section{Discussion}

The account we have given is M's construction, formed over many years in the context of extensive psychotherapy in prison. The time lapse between the murders and the interviews is long, but, as one might have expected, it has taken $\mathrm{M}$ a many years to reach the point where she would and could give informed consent to participate in a project such as this. We believe gaining consent to publish these data at all is an important opportunity.

Her case is unusual in that serial child killing is rare. There is limited information on perpetrators of murders misdiagnosed as SIDS to clarify how atypical is her case. The best data available come from Meadow's account of 81 cases of infant murders, originally thought to be due to natural causes. ${ }^{4}$ A number of features common in that series are seen in this case. Most of the dead children in Meadow's series were born to mothers who had not had a previous live, healthy child. Most of them were aged less than 7 months. In 35 of 73 pregnancies, significant problems were described, necessitating admission to hospital. Most of the infants had previously suffered unusual or unexplained events, most commonly apnoea or seizures. Nearly half the children had been discharged from hospital in the previous week. Most of the deaths occurred during the day or evening, frequently less than two hours from the last occasion when the child was seen to be normal. Most of the children were killed by their mothers, who were all white European adults. Most of the mothers smoked. Death was usually by smothering. In 24 families more than one child died.

It is possible that the features shared by $M$ and the cases in Meadow's series characterise the group of infant deaths misdiagnosed as SIDS which is likely to be later identified as not due to natural causes. One of the features, seen in $\mathrm{M}$ and in many of Meadow's families, likely to increase rate of identification, is repeated unexplained deaths in the same family.

Minimisation and denial are likely to be a feature of any perpetrator's account of their offences. Our methodology does not allow evaluation of the extent to which it is present here. What is important is M's way of talking, not her internal world or her actions. Her guilt is established. The value of the data is in presenting M's verbatim account and an aspect of how it might be to meet $M$, rather than our view of her psychological processes and actions. Postmortem data have been examined elsewhere. ${ }^{8}$

Police and court records described $M$ as having a personality disorder. DSM IV describes this as, "an enduring pattern of inner experience and behaviour that deviates markedly from the expectations of the individual's culture, is pervasive and inflexible, has an onset in adolescence or early adulthood, is stable over time and leads to distress or impairment". Diagnosis usually requires lengthy interviews and supplementary information from other informants. ${ }^{9}$ In contrast to a major mental illness (such as schizophrenia or a major mood disorder), personality disorder will often not be evident in an interaction focused on a particular role, such as "mother of ill child" or "bereaved parent". In this context, a person with a severe personality disorder may present as normal or may be particularly skilful at motivating the professional to identify with and care for her.

M's descriptions with respect to D1 of longing to be a mother, joy in her baby, distress over her baby's illness, and devastation after her first victim's death contrast starkly with her chilling descriptions of lack of connection with, and consideration of, her later victims. M's accounts of her experiences with respect to D1 indicate her ability to arouse compassion. This ability to engage trust and compassion is likely to have contributed to her gaining access to her later victims. It is possible that it allayed suspicion in professionals.

Harry and Resnick ${ }^{12}$ have described the development of post traumatic stress disorder following domestic killing, noting that being responsible for the trauma does not inure the perpetrator from experiencing a sense of horror, loss, and grief. $M$ provides insight regarding her degree of grief, even when she had been responsible for the death of D1. Her distress was misread as grief, which it was in part, but only in part.

Samuels and colleagues described how difficult judges and magistrates have found it to be convinced by video evidence. ${ }^{6}$ Schrier and Libow $^{13}$ have described the reluctance of paediatricians to suspect parents of harming their children, even in the face of considerable evidence. The value of reading M's account is in alerting health professionals as to how easy it can be to empathise with such a parent. Such empathy may contribute to natural resistance to serious consideration of evidence which indicates the parent may constitute a risk to their child.

Such an empathic response should be the initial response of any health professional. Only occasionally is it necessary to be more suspicious of the presentation of clinical problems. "Near miss cot death" may be one such circumstance, especially if the features described by Meadow are present. This case provides some self description of a person who 
successfully feigned SIDS in babies. We hope her words may assist clinicians to gain some insight into possible motivations for such behaviour.

CONCLUSIONS

Child murder is a potentially preventable cause of infant death. Identification of infant murders presented as sudden unexplained deaths is challenging to paediatricians because of paucity of data in the area and the emotional distress surrounding the death of an infant. Progress has been made in identifying features more typical of these deaths than deaths due to natural causes. ${ }^{4}$ We present descriptions from one perpetrator. The depth and intensity of her descriptions of grief is not what one might have expected in the context, and this is an important indicator to paediatricians and others involved in sudden unexplained infant deaths, not to be deterred from suspecting malevolence by heart wrenching protestations. Further investigation is needed of the cognitive processes involved for a paediatrician to shift from being the parent's ally in attempting to alleviate a child's suffering, to suspecting the parent of being the agent responsible for the child's suffering.

1 Bacon CJ. Cot death after CESDI. Arch Dis Child 1997;76:171-3.

2 Emery JL. Aviemore meeting and the gently battered child. Arch Dis Child 1983;58:75-80.

3 Taylor EM, Emery JL. Two year study of the causes of postperinatal deaths classified in terms of preventability. Arch perinatal deaths classified in

4 Meadow R. Unnatural sudden infant death. Arch Dis Child 1999;80:7-14.

5 Neglect CoCAa. Distinguishing sudden infant death syndrome from child abuse fatalities. Pediatrics 1994;94: $124-6$.

6 Samuels MP, McClaughlin W, Jacobson RR, et al. Fourteen cases of imposed upper airway obstruction. Arch Dis Child $1992 ; 67: 162-70$

7 Southall DP, Plunkett CB, Bands MW, et al. Covert video recordings of life-threatening child abuse: lessons for child protection. Pediatrics 1997;100:735-60.

8 Becroft DMO, Lockett BK. SIDS or murder. Pediatrics 1997;100:953-4.

9 American Psychiatric Association. Diagonstic and statistical manual of mental disorders, 4th edn. Washington, DC: American Psychiatric Association, 1994.

10 Stanton JM, Simpson AIF, Wouldes T. A qualitative study of filicide by mentally ill mothers. Child Abuse Neglect 2000;24:1451-60.

11 Morse JM. Designing funded qualitative research. In: Denzin NK, Lincoln YS, eds. Handbook of qualitative research. Thousand Oaks: Sage, 1994:220-36.

2 Harry B, Resnick P. Posttraumatic stress disorders in murderers. F Forensic Sci 1986;31:609-13.

13 Schrier HA, Libow JA. Hurting for love: Munchausen by proxy syndrome. New York: Guilford Press, 1993.

\section{ADC online submission and review system}

The Editors of $A D C$ are pleased to inform authors and reviewers of its new online submission and review system. Developed by Highwire Press (CA, USA), Bench>Press is a fully integrated electronic system which uses the internet to allow rapid and efficient submission of manuscripts, and for the peer review process to be conducted entirely online. We are the first journal of the BMJ publishing group to go online in this way; the aim, apart from saving trees, is to speed up the frequently frustrating progress from submission to publication.

Authors can submit their manuscript in any standard word processing software. Standard graphic formats acceptable include: .jpg, .tiff, .gif, eps, etc. The text and graphic files are automatically converted to PDF for ease of distribution and reviewing purposes. Authors are asked to approve their submission before it formally enters the reviewing process. On approval, the submission is passed to the editor and/or reviewers via the web. All transactions are secure.

To access the system click on "SUBMIT YOUR MANUSCRIPT HERE" on the ADC homepage: http://www.archdischild.com, or you can access the submission site directly at http://submit-adc.bmjjournals.com.

We are very excited with this new development and would encourage authors and reviewers to use the system where possible. It is simple to use and should greatly improve on the current peer review process. Full instructions can be found on Bench $>$ Press and ADC online. 